\title{
Physician-patient agreement on physicians' communication skills and visit satisfaction in dermatology clinics: a one-with-many design
}

\section{BACKGROUND}

There is limited research on physician-patient communication skills that covers both sides of the relationship. The aim of this study was to explore two indicators of effective physician-patient communication: the agreement of physicians' and patients' perspectives of physicians' communication skills in outpatient visits to dermatology clinics and the relationship of these perceptions of the consultation with their visit satisfaction.

\section{PARTICIPANTS AND PROCEDURE}

Dermatologists $(n=8)$ and their patients $(n=122)$ completed post-consultation dyadic measures of the content (what the physician communicates) and process (how the physician communicates) of the communication and satisfaction with a single office visit. Multilevel modelling was used to investigate the patient and doctor variance components at both the dyad and the doctor levels.

\section{RESULTS}

The patients rated the communication content skills higher than the physicians did; however, the doctors rated themselves as better skilled at the process of communication. There was disagreement between the physicians' and the patients' ratings of the both physicians' content and process skills. In contrast, there was a high level of consensus amongst patients of the same doctor about the content and process of the doctor's communication skills, while the physicians did not perceive themselves as consistent in communication between one patient and another. However, both the physicians and the patients who reported uniquely the highest physicians' communication skills had higher visit satisfaction. Moreover, the patients who perceived their physicians as having good communication process skills on average had higher visit satisfaction.

\section{CONCLUSIONS}

Although the perspectives of the same visit differed, selfrated behaviour affected satisfaction with visit.

\section{KEY WORDS}

physician communication skills; physician-patient agreement; one-with-many design; visit satisfaction 


\section{BACKGROUND}

The development of medicine and social changes have made the dominant biomedical approach to the patient-physician relationship begin to give way to patient-centred medicine. Subsequently, patients' autonomy and need for active participation in treatment decision-making have increased (Chewning et al., 2012). In addition to the predominant function of medical communication in the biomedical model, which is the provision and exchange of information, the psychosocial aspects of communication, such as fostering the patient-physician relationship, responding to patients' emotions and including patients in decision-making (cf. de Haes \& Bensing, 2009), have come into consideration. The first function requires mainly content communication skills (what physicians communicate, which includes questions and information provided to the patient). The second function is performed by process communication skills (how physicians communicate) that allow listening to and understanding the patient's perspective (Campbell et al., 2007b) and by perceptual skills that relate to internal processes of decision-making, problem-solving and awareness of beliefs and emotions about the patient and the illness (what physicians are thinking and feeling; Silverman et al., 2013).

Studies on the physician-patient relationship have focused on the course of medical visits and their effectiveness (cf. de Haes \& Bensing, 2009). Patient satisfaction is a widely used short-term outcome in physician-patient communication research (Ha \& Longnecker, 2010; Williams et al., 1998). It concerns the patient's judgement of the quality of care (Baker, 1990) and is related to patient adherence (Dréno et al., 2010; Little et al., 2001) and long-term outcomes of medical care (de Haes \& Bensing, 2009; Little et al., 2001). Much less attention has been paid to physicians' satisfaction with visits (Probst et al., 1997) and its predictors.

Research has revealed that key content communication skills such as provision of information are related to the satisfaction of patients with skin diseases and other chronic illnesses (Auerbach, 2000; cf. Kardas et al., 2013; Poot, 2009; Williams et al., 1998). Process communication skills, such as involving patients in each element of consultation (Campbell et al., 2007a; Griffin et al., 2004; Smith et al., 2011; Stewart et al., 1999), encouraging patients to ask questions (Campbell et al., 2007b; Shepherd, 2004; Stewart et al., 1999), an empathetic approach to patients (Cousin et al., 2012; Kim et al., 2004; cf. Poot, 2009) and generally high-quality communication (Kardas et al., 2013; Stewart et al., 1995), have also been found to relate to positive patients' outcomes (Little et al., 2001; van Osch et al., 2017); however, the results are somewhat inconsistent across studies (van den Brink-Muinen et al., 2000; Stewart et al., 2011). On the one hand, pa- tients with different chronic health conditions have emphasised the importance of content (access to information) rather than process communication skills (van den Brink-Muinen et al., 2000; Jenkins et al., 2001). On the other hand, physicians can be regarded as an important source of psychological support (Baile et al., 2000), and their disregard of psychosocial aspects of disease might be perceived negatively by patients (Magin et al., 2009; Richards et al., 2004) and be related to less satisfaction and enablement to cope with the somatic problem (Little et al., 2001).

Another indicator of effective physician-patient communication is agreement on the perception of medical communication (Röttele et al., 2020), which shows the degree of mutual understanding between doctor and patient and is related to adherence to treatment (cf. Kenny et al., 2010; Sewitch et al., 2003), health outcomes (Staiger et al., 2005) and post-visit satisfaction (Fagerberg et al., 1999; Sewitch et al., 2003; Staiger et al., 2005; Zandbelt et al., 2004). However, the results on concordance between both sides of the relationship during the consultation are inconsistent. A few studies have revealed differences (zero or near-zero correlation) in physicians' and patients' perceptions of doctors' communication skills (Burt et al., 2018; Campbell et al., 2007a; Hall et al., 1999; Kenny et al., 2010; Overeem et al., 2012; Sewitch et al., 2003). Findings from other studies, using simpler statistical methods (descriptive data and proportional index/kappa coefficient), suggested an average (Coran et al., 2013) or high level of agreement in responses (Ahlén et al., 2007; Fagerberg et al., 1999).

The patient-doctor relationship could be a pivotal aspect of the long-term treatment of chronic skin diseases (Linder \& Forchetti, 2009; Uhlenhake et al., 2010; World Health Organization, 2016), whose highly visible symptoms increase the likelihood of stigmatisation (Barankin \& DeKoven, 2002; Taube, 2016) and psychological distress (Richards et al., 2004) and decrease quality of life (Kowalewska et al., 2020; Miniszewska et al., 2020). However, there is little research on the doctor-patient relationship in dermatology and how it relates to post-visit outcomes (cf. Abbott, 2017). Most studies on dermatologists' communication skills have been qualitative (Linder et al., 2009; Magin et al., 2009) and did not analyse both sides of the physician-patient relationship simultaneously. Therefore, the use of standard measures and more advanced statistical analysis, including dyadlevel statistics, is justified.

\section{RESEARCH PROBLEMS}

To address the gaps in previous studies, especially in the dermatology field, the simultaneous perspectives of the physicians themselves and their patients about the physicians' communication skills were as-
Patient-physician agreement on physicians' communication skills 
sessed. While the results of previous studies indicate different levels of physician and patient ratings of the same visit (Ahlén et al., 2007; Burt et al., 2018; Fagerberg et al., 1999; Kenny et al., 2010), it is still unclear to what extent patients of the same physician vary in their ratings.

The present study focused on two broad aspects of practitioner communication - content and process skills - referring to both models of medical interview, the traditional clinical method and a communication model (Kurtz et al., 2003).

In view of the lack of consistent research results indicating which communication skills are more crucial for visit satisfaction (van den Brink-Muinen et al., 2000; Stewart et al., 2011) and the psychosocial difficulties and experience with medical care of patients with skin diseases, both types of communication skills relating to visit satisfaction should be analysed.

Thus, the first aim of the present study was to determine whether there is congruence between patients and practitioners in perceptions of physicians' content and process of communication. Additionally, with regard to inconsistent results, the agreement between patients' perspectives of the same dermatologists was analysed. Second, the relationships between physicians' and patients' perceptions of communication skills and their visit satisfaction were examined. It was expected that both physicians' and patients' ratings of communication skills and the patients' perspectives of the same physician would be convergent. In terms of visit satisfaction, it was predicted that the higher both physicians' and patients' ratings of content and process skills, the higher their visit satisfaction would be.

The following hypotheses were tested:

There would be agreement between physicians' self-perception of their communication skills and patients' perceptions of them.

There would be agreement between patients of the same physician on the physician's communication skills.

There would be positive relationships between patients' and physicians' communication skills ratings and visit satisfaction.

\section{PARTICIPANTS AND PROCEDURE}

\section{PARTICIPANTS}

The sample consisted of 8 dermatologists $(87.5 \%$ women) aged $32-59(M=38.29, S D=3.73)$ and 122 of their patients (60.2\% women) aged $18-73(M=46.10$, $S D=1.79)$. Over $62 \%$ of the physicians and $65 \%$ of the patients were married or partnered, and most of the patients $(89.4 \%)$ reported at least a high school education.
The mean time since physician-confirmed diagnosis of dermatological disease was 105.58 months $(S D=19.60)$. The most frequent chronic dermatological diseases were psoriasis $(n=29,22.7 \%)$ and atopic dermatitis $(n=24,18.8 \%)$. On average, the patients had had 4.37 visits to the same physician $(S D=0.83)$, waiting an average of 1.31 months for the consultation $(S D=0.89)$. All sociodemographic and clinical data are presented in Table 1.

In all, there were 122 physician-patient dyads. The mean number of patients per doctor was 11.18 $(S D=8.18$, range $3-32)$.

\section{MEASURES}

Content and process of the physicians' communication. The content and process communication skills were assessed with both the patient-rated and physicianrated versions of the Matched-Pair Instrument (MPI; Campbell et al., 2007b). A back-translation method was used to translate the MPI questionnaire into Polish. The MPI is a 19-item measure of both the content (4 items, including explanation and planning next steps) and the process (15 items, including patient greeting, attentive listening, responding and involving the patient in decision-making) of physicians' communication skills rated on a 5-point scale, ranging from 1 (strongly disagree) to 5 (strongly agree). The overall score for the content and process subscales were the sum of the 4 and 15 ratings, respectively. The higher the results, the higher is the level of these two aspects of communication during a given visit. Cronbach's $\alpha$ for the physician was .92 for content and .96 for process subscales. Cronbach's $\alpha$ for the patient was .80 for content and .94 for process subscales, respectively.

Visit satisfaction. Satisfaction was assessed with both the patient rating and the doctor rating of one item from the MPI (for the physician: "Overall, I was satisfied with this consultation today" and for the patient: "Overall, I was satisfied with my visit to the doctor today"; Campbell et al., 2007b) on a 5-point scale (higher scores denote higher satisfaction with a single visit).

\section{STATISTICAL ANALYSIS}

To examine the agreement amongst the patients of the same physician and the patients' and the physicians' ratings of the physicians' communication skills, multilevel modelling for a reciprocal (physician- and patient-provided data) one-with-many-design (many patients linked with one physician) was employed using IBM SPSS v. 25.

Multilevel modelling was used to investigate different variance components for both the physicians' 
Table 1

Sociodemographic and clinical characteristics of participants

\begin{tabular}{|c|c|c|}
\hline \multirow[t]{2}{*}{ Characteristics } & Patients $(n=122)$ & Physicians $(n=8)$ \\
\hline & $n(\%)$ & $n(\%)$ \\
\hline \multicolumn{3}{|l|}{ Demographic } \\
\hline Women & $77(60.2)$ & $7(87.5)$ \\
\hline Age in years $(M \pm S D / m e d i a n)$ & $46.10 \pm 1.79 / 45.5$ & $38.29 \pm 3.73 / 34.0$ \\
\hline Marital status: married/partnered & $84(65.6)$ & $5(62.6)$ \\
\hline Employment (yes) & $73(57)$ & \\
\hline Length of service (years) $(M \pm S D /$ median $)$ & & $11.71 \pm 3.98 / 7.0$ \\
\hline Weekly working hours $(M \pm S D /$ median $)$ & & $46.86 \pm 7.16 / 50.0$ \\
\hline Children (yes) & $76(59.4)$ & $4(50.0)$ \\
\hline \multicolumn{3}{|l|}{ Education } \\
\hline Elementary school education & $1(8.0)$ & \\
\hline Basic vocational education & $9(7.0)$ & \\
\hline High school education & $45(35.2)$ & \\
\hline University education & $65(50.8)$ & $8(100)$ \\
\hline \multicolumn{3}{|l|}{ Clinical } \\
\hline $\begin{array}{l}\text { Duration of dermatological disease (months) } \\
(M \pm S D / \text { median })\end{array}$ & $105.58 \pm 19.60 / 36.0$ & \\
\hline \multicolumn{3}{|l|}{ Primary diagnosis } \\
\hline Psoriasis & $29(22.7)$ & \\
\hline Atopic dermatitis & $24(18.8)$ & \\
\hline Acne & $16(12.5)$ & \\
\hline Pigmented naevus & $14(10.9)$ & \\
\hline Itchiness & $13(10.2)$ & \\
\hline Undiagnosed skin condition & $11(8.6)$ & \\
\hline Contact dermatitis & $4(3.1)$ & \\
\hline Lupus & $4(3.1)$ & \\
\hline Urticaria & $3(2.3)$ & \\
\hline Seborrheic dermatitis & $3(2.3)$ & \\
\hline Herpes & $3(2.3)$ & \\
\hline Other skin condition & $31(24.2)$ & \\
\hline Number of visits to the same doctor $(M \pm S D /$ median $)$ & $4.37 \pm 0.83 / 1.0$ & \\
\hline Waiting time for the consultation $(M \pm S D /$ median $)$ & $1.31 \pm 0.89 / 1.0$ & \\
\hline
\end{tabular}

and the patients' ratings of physicians' communication skills (content and process) at two levels: the dyad level (within variance) and the physician level (between variance).

At the dyad level, the variance component represented the variability in the physicians' and their patients' ratings of the physicians' communication skills, removing the mean for physicians (Kenny et al., 2010). A dyadic reciprocity correlation was computed to examine the relationships within the physician group between the patients' and the physicians' ratings of communications skills. At the doctor 
level, the variance component represented the variability in the physicians' and their patients' ratings of the physicians' communication skills between physicians.

To determine whether the physicians who rated themselves as good in communication skills with their patients were perceived as such by their patients (hypothesis 1), the dyadic reciprocity correlation (dyad level) and generalised reciprocity (physician-level) correlation were estimated.

To test the congruence in perception of the dermatologists' communication skills between patients of the same physician (hypothesis 2), two interclass correlations (ICC) were computed from the multilevel modelling. The ICC assessed the proportion of the variance due to the physician on the physicians' communication skills ratings of both the patients and the physicians. A higher value indicated high agreement amongst the patients of the same physician about communication skills (ICC for patients) and high consensus between ratings of the same physician (ICC for physician).

Finally, to answer the third question about the relation between the patients' and the physicians' communication skills ratings and their satisfaction (hypothesis 3), two multilevel models were conducted for process and content skills separately. For these analyses, process and content skills ratings were transformed to separate variances related to the dyad level and the physician level of these variables. Following Bolger and Laurenceau (2013), doctor-level communication skills were calculated by aggregating individual ratings of communication skills (separately for the process and the content communication skills), which resulted in stable values for each person. These values were then subtracted from the rating of a single visit, which resulted in the residual communication skills values. Thus, two orthogonal components were obtained, with the dyad level interpreted as changes from the mean rating of com-

\section{Table 2}

Definitions of variance and correlation parameters

\begin{tabular}{|c|c|}
\hline Parameter & Definition \\
\hline $\begin{array}{l}\text { Physician } \\
\text { (Physician_process, Physician_content; } \\
\text { Table 1) }\end{array}$ & $\begin{array}{l}\text { The physician-rated version of the process (Tables } 1 \& 4 \text { ) } \\
\text { and content communication skills (Tables } 1 \& 5)\end{array}$ \\
\hline $\begin{array}{l}\text { Patient } \\
\text { (Physician_process, Physician_content; } \\
\text { Table 1) }\end{array}$ & $\begin{array}{l}\text { The patient-rated version of the process (Tables } 1 \& 4 \text { ) } \\
\text { and content communication skills (Tables } 1 \& 5 \text { ) }\end{array}$ \\
\hline \multicolumn{2}{|l|}{ Parameter level } \\
\hline \multicolumn{2}{|l|}{ Dyad (within variance) } \\
\hline $\begin{array}{l}\text { Relationship variance (plus error) } \\
\text { for physician }\end{array}$ & $\begin{array}{l}\text { Variability on patients' communication skills ratings } \\
\text { within physicians }\end{array}$ \\
\hline $\begin{array}{l}\text { Relationship (plus error) variance } \\
\text { for patient }\end{array}$ & $\begin{array}{l}\text { Variability on physicians' communication skills ratings } \\
\text { within physicians }\end{array}$ \\
\hline Dyadic reciprocity correlation & $\begin{array}{l}\text { Relationship between physicians' communication skills } \\
\text { ratings and scores from his/her own patients (within } \\
\text { physician) }\end{array}$ \\
\hline \multicolumn{2}{|l|}{ Individual (between variance) } \\
\hline Physician variance & $\begin{array}{l}\text { Variability in physicians' communication skills ratings } \\
\text { from one physician to another physician }\end{array}$ \\
\hline Patient variance & $\begin{array}{l}\text { Variability in patients' communication skills ratings } \\
\text { between physicians }\end{array}$ \\
\hline Generalised reciprocity correlation & $\begin{array}{l}\text { Relationship between the mean physcian's communication } \\
\text { skills ratings and the average score }\end{array}$ \\
\hline ICC for physician & $\begin{array}{l}\text { Proportion of the variance due to physician for the } \\
\text { physician's communication skills ratings }\end{array}$ \\
\hline ICC for patients & $\begin{array}{l}\text { Proportion of the variance due to physician in the } \\
\text { communication skills ratings of patients }\end{array}$ \\
\hline
\end{tabular}


munication skills typical for a given physician and the physician level interpreted as individual differences in ratings of communication skills between physicians and patients, separately. Additionally, the physician-level communication skills were centred on the grand mean. Definitions of variance and correlation parameters are found in Table 2.

\section{RESULTS}

\section{PRELIMINARY ANALYSES}

The descriptive statistics of the content and process communication skills and the satisfaction of both physicians and patients are presented in Table 3.

The patients rated the physicians' performance on content communication skills more highly than the physicians rated themselves, whereas the physicians rated themselves higher than the patients on process skills and visit satisfaction.

Hypothesis 1: There would be agreement between physicians' self-perception of their communication skills and patients' perceptions of them

The lower panel of Table 3 presents the different variance components and correlation for both the physicians' and the patients' ratings of the physicians' process of communication skills as the results of the multilevel modelling. As shown in the lower panel of Table 3, at the dyadic level, the correlation between the patient and the physician process skills ratings (the dyadic reciprocity correlation) was weak and not significant $(r=.15, p=.107)$. There was no agreement in the patients' and physicians' ratings of process communication skills during a given visit.

Also, the correlation between the patient and the physician ratings of process skills at the individual level (the generalised reciprocity correlation) was weak and not significant $(r=.18, p=.700)$.
Similar results (see lower panel of Table 4) were obtained for the content of communication skills there were no significant correlations between the patient and the physician ratings of this type of communication skill at the dyadic level $(r=.00, p=.993)$ and the individual level $(r=.77, p=.273)$.

Hypothesis 2: Agreement between patients of a specific physician on physicians' communication skills

First, the different variance components for the process (Table 3 ) and the content (Table 4) of communication skills at both the dyad level and the individual (physician) level were analysed. The first two dyadlevel variance terms in the lower panel of Table 3 indicate that there was more relationship variance for the physician than for the patients (85.95 vs. 12.25), which indicates that the physicians' self-rating process communication skills vary much more from one patient to another patient for the same physician than across patients.

Similarly, the variation in the mean perception of the physicians (individual level) revealed that the variance in the patients' ratings of process skills was smaller than amongst the physicians (14.76 vs. 18.37); neither was statistically significant.

Similar analyses were conducted for the content communication skills (Table 4), revealing only significant relationship variances for both the patients and the physicians. At the dyad level, the variance for the patients was much smaller than for the physicians (0.54 vs. 9.98), which indicates a higher level of variability in the physicians' ratings of the content communication skills in contrast to a high level of similarity in the patients' ratings.

The variation in the mean perception of the physicians' content communication skills showed that the variance for patients was slightly smaller than for the physicians (.77 vs. .87); neither was significant.

The ICCs for the patients of the same physician for both the process and the content communica-
Patient-physician agreement on physicians' communication skills

\section{Table 3}

Descriptive statistics

\begin{tabular}{|c|c|c|c|c|c|c|}
\hline \multirow[t]{2}{*}{ Variable } & \multirow[t]{2}{*}{$M$} & \multirow[t]{2}{*}{$S D$} & \multirow[t]{2}{*}{ Range } & \multicolumn{2}{|c|}{$95 \% \mathrm{Cl}$} & \multirow[t]{2}{*}{ Cronbach's $\alpha$} \\
\hline & & & & Lower bound & Upper bound & \\
\hline Physician_content & 13.78 & 0.42 & $12-15$ & 12.84 & 14.72 & .97 \\
\hline Patient_content & 16.68 & 0.42 & $4-20$ & 15.70 & 17.66 & .94 \\
\hline Physician_process & 63.98 & 1.77 & $14-56$ & 59.98 & 67.97 & .81 \\
\hline Patient_process & 59.25 & 1.57 & $56-90$ & 55.64 & 62.86 & .79 \\
\hline Physician_satisfaction & 4.50 & 0.15 & $3-5$ & 4.17 & 4.83 & - \\
\hline Patient_satisfaction & 4.32 & 0.13 & $1-5$ & 4.02 & 4.62 & - \\
\hline
\end{tabular}


Table 4

Parameter estimates for the multilevel model of process skills $(N=122$ dyads $)$

\begin{tabular}{|c|c|c|c|c|c|c|}
\hline \multirow[t]{2}{*}{ Fixed effects } & \multirow[t]{2}{*}{ Estimate } & \multirow[t]{2}{*}{$S E$} & \multirow[t]{2}{*}{$t$} & \multirow[t]{2}{*}{$p$} & \multicolumn{2}{|c|}{$95 \% \mathrm{Cl}$} \\
\hline & & & & & Lower & Upper \\
\hline Physician & 65.84 & 1.57 & 41.98 & $<.001$ & 62.15 & 69.52 \\
\hline Patient & 60.31 & 1.68 & 35.97 & $<.001$ & 56.11 & 64.52 \\
\hline \multirow[t]{2}{*}{ Random effects } & Estimate & $S E$ & $z$ & $p$ & \multicolumn{2}{|c|}{$95 \% \mathrm{Cl}$} \\
\hline & & & & & Lower & Upper \\
\hline \multicolumn{7}{|l|}{ Dyad (within variance) } \\
\hline $\begin{array}{l}\text { Relationship variance (plus error) } \\
\text { for physician }\end{array}$ & 85.96 & 11.44 & 7.51 & $<.001$ & 66.21 & 111.58 \\
\hline $\begin{array}{l}\text { Relationship (plus error) variance } \\
\text { for patient }\end{array}$ & 12.25 & 1.62 & 7.56 & $<.001$ & 9.45 & 15.88 \\
\hline Dyadic reciprocity correlation & .15 & .09 & 1.61 & .107 & -.03 & .32 \\
\hline \multicolumn{7}{|l|}{ Individual (between variance) } \\
\hline Physician variance & 18.38 & 10.33 & 1.78 & .075 & 6.10 & 55.31 \\
\hline Patient variance & 14.76 & 12.92 & 1.14 & .253 & 2.66 & 82.02 \\
\hline Generalised reciprocity correlation & .18 & .46 & .38 & .700 & -.64 & .81 \\
\hline
\end{tabular}

tion were respectively .55 and .53 . The relationship (plus error) accounted for the remaining 45\% (for the process skills) and $47 \%$ (for the content skills) of the variance. This represents a consensus about the physician's communication skills amongst the patients of the same dermatologist, which supported the hypothesis.

Additionally, the ICCs for the physicians were also considered. The ICC for process skills was .18, and for the content skills it was -.08. The physicians perceived that their communication skills varied from one patient to another.

Hypothesis 3: Relationship between physicians' and patients' ratings of physicians' communication skills (process and content skills separately) and their satisfaction

Finally, we examined the relation between communication skills and visit satisfaction. Table 5 presents the results for the multilevel modelling of satisfaction as a function of the patient-rated and the physician-rated process communication skills. As can be seen in the upper panel of Table 5, which illustrates the fixed effects, there were significant physicianspecific and dyad-specific effects on visit satisfaction level. As expected, higher than average values of both patient and physician process communication skills ratings were related to their higher satisfaction. The dyad-specific results indicated similar re- sults - the patients' and the physicians' relationship effects were associated with visit satisfaction. The covariances in the lower panel of Table 5 reflect the dyad-level nonindependence of the physicians' and the patients' visit satisfaction following the process communication.

Also, a significant effect of the average physicianrated content communication skills was noted (Table 6), whereas the effect of the average patient-rated content communication skills was insignificant. At the dyadic level, both the patient-rated and the physician-rated content communication skills during a given encounter were related to higher satisfaction. On visits with typical content communication performed by physicians, both the physicians and the patients reported satisfaction with visit level means of 4.93 and 4.13 points, respectively. The dyad-specific results indicated similar results: the patients' and the physicians' relationship effects were associated with visit satisfaction.

\section{DISCUSSION}

This study aimed to examine the agreement between physicians' self-rated and patient-rated physicians' communication skills during a single visit and between patients of the same dermatologist and the relationships of these evaluations with post-visit satisfaction. 
Table 5

Parameter estimates for the multilevel model of content skills $(N=122$ dyads)

\begin{tabular}{|c|c|c|c|c|c|c|}
\hline \multirow[t]{2}{*}{ Fixed effects } & \multirow[t]{2}{*}{ Estimate } & \multirow[t]{2}{*}{$S E$} & \multirow[t]{2}{*}{$t$} & \multirow[t]{2}{*}{$p$} & \multicolumn{2}{|c|}{$95 \% \mathrm{Cl}$} \\
\hline & & & & & Lower & Upper \\
\hline Physician & 14.26 & 0.34 & 41.99 & $<.001$ & 13.46 & 15.06 \\
\hline Patient & 16.95 & 0.42 & 40.33 & $<.001$ & 15.58 & 18.32 \\
\hline \multirow[t]{2}{*}{ Random effects } & \multirow[t]{2}{*}{ Estimate } & \multirow[t]{2}{*}{$S E$} & \multirow[t]{2}{*}{$z$} & \multirow[t]{2}{*}{$p$} & \multicolumn{2}{|c|}{$95 \% \mathrm{Cl}$} \\
\hline & & & & & Lower & Upper \\
\hline \multicolumn{7}{|l|}{ Dyad (within variance) } \\
\hline $\begin{array}{l}\text { Relationship variance (plus error) } \\
\text { for physician }\end{array}$ & 9.98 & 1.40 & 7.12 & $<.001$ & 7.59 & 13.16 \\
\hline $\begin{array}{l}\text { Relationship (plus error) variance } \\
\text { for patient }\end{array}$ & .54 & .07 & 7.55 & $<.001$ & .42 & .70 \\
\hline Dyadic reciprocity correlation & .00 & .10 & .01 & .993 & -.18 & .18 \\
\hline \multicolumn{7}{|l|}{ Individual (between variance) } \\
\hline Physician variance & .86 & .48 & 1.79 & .074 & .29 & 2.59 \\
\hline Patient variance & .67 & 1.00 & .67 & .505 & .04 & 12.61 \\
\hline Generalised reciprocity correlation & .77 & .70 & 1.10 & .273 & -.98 & 1.00 \\
\hline
\end{tabular}

Table 6

Parameter estimates for multilevel model of satisfaction as a function of process skills $(N=122$ dyads)

\begin{tabular}{|c|c|c|c|c|c|c|}
\hline \multirow[t]{2}{*}{ Fixed effects } & \multirow[t]{2}{*}{ Estimate } & \multirow[t]{2}{*}{$S E$} & \multirow[t]{2}{*}{$t$} & \multirow[t]{2}{*}{$p$} & \multicolumn{2}{|c|}{$95 \% \mathrm{Cl}$} \\
\hline & & & & & Lower & Upper \\
\hline Physician intercept & 4.34 & .03 & 141.26 & $<.001$ & 4.28 & 4.40 \\
\hline Patient intercept & 4.52 & .05 & 90.17 & $<.001$ & 4.42 & 4.62 \\
\hline Physician between-person process skills & .06 & .01 & 8.51 & $<.001$ & .05 & .08 \\
\hline Patient between-person process skills & .06 & .01 & 4.32 & $<.001$ & .03 & .08 \\
\hline Physician within-person process skills & .08 & .01 & 13.95 & $<.001$ & .07 & .09 \\
\hline Patient within-person process skills & .07 & .00 & 14.23 & $<.001$ & .06 & .08 \\
\hline \multirow[t]{2}{*}{ Random effects } & \multirow[t]{2}{*}{ Estimate } & \multirow[t]{2}{*}{$S E$} & \multirow[t]{2}{*}{$z$} & \multirow[t]{2}{*}{$p$} & \multicolumn{2}{|c|}{$95 \% \mathrm{Cl}$} \\
\hline & & & & & Lower & Upper \\
\hline \multicolumn{7}{|l|}{ Level 1 (within-dyad) } \\
\hline Physician residual & .22 & .02 & 8.89 & $<.001$ & .18 & .27 \\
\hline Patient residual & .14 & .01 & 8.89 & $<.001$ & .11 & .17 \\
\hline Physician-patient residual covariance & -.04 & .08 & -.56 & .577 & -.20 & .11 \\
\hline \multicolumn{7}{|l|}{ Level 2 (between-dyad) } \\
\hline Physician intercept & .00 & .00 & & & & \\
\hline Patient intercept & .00 & .00 & & & & \\
\hline Physician-patient intercept covariance & .12 & .00 & & & & \\
\hline
\end{tabular}


Table 7

Parameter estimates for multilevel model of satisfaction as a function of content communication skills $(N=122$ dyads $)$

\begin{tabular}{|c|c|c|c|c|c|c|}
\hline \multirow[t]{2}{*}{ Fixed effects } & \multirow[t]{2}{*}{ Estimate } & \multirow[t]{2}{*}{$S E$} & \multirow[t]{2}{*}{$t$} & \multirow[t]{2}{*}{$p$} & \multicolumn{2}{|c|}{$95 \% \mathrm{Cl}$} \\
\hline & & & & & Lower & Upper \\
\hline Physician intercept & 4.93 & .08 & 65.25 & $<.001$ & 4.76 & 5.08 \\
\hline Patient intercept & 4.13 & .11 & 35.95 & $<.001$ & 3.84 & 4.42 \\
\hline Physician between-person process skills & .25 & .06 & 4.37 & .005 & .11 & .39 \\
\hline Patient between-person process skills & .20 & .11 & 1.88 & .121 & -.08 & .49 \\
\hline Physician within-person process skills & .27 & .04 & 7.00 & $<.001$ & .19 & .34 \\
\hline Patient within-person process skills & .14 & .02 & 7.57 & $<.001$ & .10 & .17 \\
\hline \multirow[t]{2}{*}{ Random effects } & Estimate & $S E$ & $z$ & $p$ & \multicolumn{2}{|c|}{$95 \% \mathrm{Cl}$} \\
\hline & & & & & Lower & Upper \\
\hline
\end{tabular}

Level 1 (within-dyad)

$\begin{array}{lrrrrrr}\text { Physician residual } & .36 & .04 & 8.69 & <.001 & .29 & .45 \\ \text { Patient residual } & .20 & .02 & 8.70 & <.001 & .16 & .25 \\ \text { Physician-patient residual covariance } & .00 & .08 & .04 & .965 & -.16 & .17\end{array}$

Level 2 (between-dyad)

\begin{tabular}{lrrrrrr} 
Physician intercept & .01 & .01 & .91 & .364 & .00 & .10 \\
Patient intercept & .03 & .03 & 1.12 & .264 & .01 & .20 \\
Physician-patient intercept covariance & -.62 & .55 & -1.13 & .258 & -.99 & .78 \\
\hline
\end{tabular}

Contrary to our hypothesis, the findings revealed disagreement between the dermatologists' self-perception of content and process communication skills and their patients' perception of the same. These differences in actor-observer perceptions generally support previous findings that demonstrated either no (Burt et al., 2018; Campbell et al., 2007a; Overeem et al., 2012) or low agreement (Kenny et al., 2010; Röttele et al., 2020).

Similar results - weak self-observer agreement - were obtained in personality psychology experiments (Gosling et al., 1998), which might result from difficulty tracking actors' observable behaviours rather than their emotional states and thoughts (Andersen et al., 1998) or bias in observer ratings (their differential interpretations of the rating scale and their differential evaluations of the particular targets; Hoyt \& Kerns, 1999). Differences in ratings of physicians' communication skills may be due to the content of communication being evaluated, the training history of the raters (Chesser et al., 2013; cf. Röttele et al., 2021) and social desirability (Worthington et al., 2000). However, higher self-observer agreement has been correlated with observability, social desirability, frequency of acts and personality traits
(Gosling et al., 1998). Our findings suggest that future studies on the course of behaviour during a medical visit should include more stable factors, such as patients' and/or physicians' preferences for communication skills (Bell et al., 2002; Cousin et al., 2012), role orientation (Gafni et al., 1998; Krupat et al., 2000) and personality (Cousin et al., 2013).

It was also hypothesised that patients of the same physician would be congruent in how they perceived their physician's communications skills. This hypothesis was supported with regard to both process and content communication skills. The results imply that patients of the same physician and between physicians perceived them as more stable in behaviour than did the physicians. One explanation for this discrepancy could be that physicians are objectively consistent and conventional in their level of communication skills or that patients use stereotypes in their perception of their dermatologist and their ratings were affected by social approval. The patients' perspectives could be homogeneous due to the nature of the visit concerning skin diseases. For dermatologists, this could mean that they were convinced that they adapt to a specific relationship with a single patient. Different perceptions of the same encounter 
were also observed in a study by Kenny et al. (2010): in contrast to our results, patients of the same physician did not agree much with each other about the level of physician communication skills, whereas the physicians' perspective was more consistent across consultations. These results have a concrete meaning for this particular relationship. It appeared that physicians did not notice that what they experienced as good communication was not necessarily experienced in the same way by their patients. This lack of understanding could be a barrier in improving their communication practices, which could be overcome by recording the visit or bringing in an outside observer (Burt et al., 2018). However, even with this solution, ratings between observers, patients and physicians may differ (cf. Röttele et al., 2020).

The third hypothesis concerned the effects of perceived physicians' communication skills on visit satisfaction. The results show that the physicians who rated themselves generally and during a given visit as good in content and process communication skills were more satisfied. Conversely, the more satisfied patients were also those who perceived their physicians as competent in both types of communication skills and those who generally saw their dermatologist as good in process skills such as patient greeting, listening, and understanding (Bensing, 1991).

Thus, the average level of content communication skills rated by the patients was not related to shortterm outcome. This is consistent with an understanding of patients from a biopsychosocial perspective and the need to consider patient-centred communication style during medical face-to-face encounters, including both medical and psychosocial aspects of communication (cf. Janssen \& Largo-Janssen, 2012). Simultaneously, physician instrumental behaviour (content skills of communication) showed stronger relationships with satisfaction than affective behaviours (the way information was provided), which coincides with part of other findings (Ong et al., 1995; cf. Williams et al., 1998). Notably, patients' preferences for more content or process communication skills may depend on the seriousness of the disease and the patients' psychological characteristics and emotional state (cf. Cousin et al., 2012).

Inconsistent with other studies assessing physicians' performance (cf. Burt et al., 2018; Campbell et al., 2007a; Kenny et al., 2010), physicians scored themselves a little higher on process skills of communication and lower on content communication skills than did patients. Similar to Campbell et al. (2007a), most of the ratings by dermatologists were 4-5 out of 5; however, the range of patients' ratings was more heterogeneous. Paradoxically, these results could be related to the social desirability and medical knowledge and biomedical orientation of physicians, who evaluated themselves on the basis of medical standards, being stricter in assessing those skills, whereas the patients judged the way that the care was delivered (process skills; cf. Taylor, 2012). The results could be an example of the growing number of patients who prefer to participate in the decisionmaking process (discussing treatment options and receiving information; Chewning et al., 2012) and the idiosyncrasies of a particular health care system. Different skill ratings between patients and dermatologists may reflect the health care system in a given country. Extensive work by the European Commission (OECD/EU, 2016) has shown that for different aspects of patients' experience with the health care system (quality of family doctor, enough time with a doctor during consultation and being involved in care and treatment decisions), Poland has the lowest rates in the whole European Union. Interventions aimed at improving doctors' communication practices (Wlodarczyk et al., 2017) may improve health care provision (Olson \& Windish, 2010).

\section{STUDY LIMITATIONS}

This study has several limitations. First, given the heterogeneity of the sample, it was medium-sized and comprised patients with different skin diseases (up to $25 \%$ with unidentified skin conditions). The study relied on self-report indices, but inclusion of external peer raters might not change the results. Studies have shown that physicians' and patients' or external observers' perspectives (Burt et al., 2018; Hall et al., 1999; Violato \& Lockyer, 2006) or audiorecording results (Behrend et al., 2011) are discordant. Subjective experiences of patients and direct observations of behaviour could not independently predict patients' satisfaction (cf. Saba et al., 2006). An inadequate assessment by physicians of their own behaviour suggests the need to provide professional feedback from an external peer observer (Burt et al., 2018; Violato \& Lockyer, 2006) or audio-record the visit.

Furthermore, physicians rated their communication skills after visits from patients whom they knew would also assess their behaviour, which definitely could have affected the results (the Hawthorne effect; c.f. McCambridge et al., 2014). A change in the procedure and organisation of the study is recommended.

Moreover, there is a need to assess patients' emotional state, which might affect patients' perception (Street \& Wiemann, 1987) and post-visit satisfaction (cf. Williams et al., 1998). The patients' attitudes towards communication style could also have a direct impact on patients' satisfaction with visits (Cousin et al., 2012) or moderate patients' reactions to physician behaviour. In the context of skin diseases, not only the short-term effects of office encounters but also the long-term effects on outcomes should be analysed.
Patient-physician agreement on physicians' communication skills 


\section{CONCLUSIONS}

These results are of considerable practical significance. Although the perspectives of the same visit differ, still self-rated behaviour affected satisfaction. This suggests that physicians could shape their own activities to enhance both patients' and their own satisfaction.

\section{ACKNOWLEDGEMENTS}

Zuzanna Kwissa-Gajewska, Aleksandra Kroemeke

The study was supported by the Polish Ministry of Science and Higher Education core funding for statutory research activity: grant WP/2015/A/17, University of Social Sciences and Humanities, Faculty of Psychology.

\section{References}

Abbott, P. (2017). Patient-centred health care for people with chronic skin conditions. British Journal of Dermatology, 177, 329-330. https://doi.org/ 10.1111/bjd. 15709

Ahlén, G., Mattsson, B., \& Gunnarsson, R. (2007). Physician patient questionnaire to assess physician patient agreement at the consultation. Family Practice, 24, 498-503. https://doi.org/10.1093/ fampra/cmm043

Andersen, S. M., Glassman, N. S., \& Gold, D. A. (1998). Mental representations of the self, significant others, and nonsignificant others: Structure and processing of private and public aspects. Journal of Personality and Social Psychology, 75, 845-861. https://doi.org/10.1037//0022-3514.75.4.845

Auerbach, S. M. (2000). Should patients have control over their own health care: Empirical evidence and research issues. Annals of Behavioral Medicine, 22, 246-259. https://doi.org/10.1007/BF02895120

Baile, W. F., Buckman, R., Lenzi, R., Glober, G., Beale, E. A., \& Kudelka, A. P. (2000). SPIKES - a sixstep protocol for delivering bad news: Application to the patient with cancer. The Oncologist, 5, 302311. https://doi.org/10.1634/theoncologist.5-4-302

Baker, R. (1990). Development of a questionnaire to assess patients' satisfaction with consultations in general practice. The British Journal of General Practice, 40, 487-490.

Barankin, B., \& DeKoven, J. (2002). Psychosocial effect of common skin diseases. Canadian Family Physician, 48, 712-716.

Behrend, L., Maymani, H., Diehl, M., Gizlice, Z., Cai, J., \& Sheridan, S. L. (2011). Patient-physician agreement on the content of CHD prevention discussions. Health Expectations, 14, 58-72. https:// doi.org/10.1111/j.1369-7625.2010.00614.x

Bell, R. A., Kravitz, R. L., Thom, D., Krupat, E., \& Azari, R. (2002). Unmet expectations for care and the patient-physician relationship. Journal of General Internal Medicine, 17, 817-824. https://doi. org/10.1046/j.1525-1497.2002.10319.x

Bensing, J. (1991). Doctor-patient communication and the quality of care. Social Science \& Medicine, 32, 1301-1310. https://doi.org/10.1016/02779536(91)90047-g

Bolger, N., \& Laurenceau, J. P. (2013). Methodology in the social sciences. Intensive longitudinal methods: an introduction to diary and experience sampling research. Guilford Press.

Burt, J., Abel, G., Elliott, M. N., Elmore, N., Newbould, J., Davey, A., Llanwarne, N., Maramba, I., Paddison, C., Campbell, J., \& Roland, M. (2018). The evaluation of physicians' communication skills from multiple perspectives. Annals of Family Medicine, 16, 330-337. https://doi.org/10.1370/afm.2241

Campbell, T. A., Auerbach, S. M., \& Kiesler, D. J. (2007a). Relationship of interpersonal behaviors and health-related control appraisals to patient satisfaction and compliance in a university health center. Journal of American College Health, 55, 333340. https://doi.org/10.3200/JACH.55.6.333-340

Campbell, C., Lockyer, J., Laidlaw, T., \& Macleod, H. (2007b). Assessment of a matched-pair instrument to examine doctor-patient communication skills in practising doctors. Medical Education, 41, 123-129. https://doi.org/10.1111/j.1365-2929.2006.02657.x

Chesser, A., Reyes, J., Woods, N. K., Williams, K., \& Kraft, R. (2013). Reliability in patient-centered observations of family physicians. Family Medicine, 45, 428-432.

Chewning, B., Bylund, C. L., Shah, B., Arora, N. K., Gueguen, J. A., \& Makoul, G. (2012). Patient preferences for shared decisions: a systematic review. Patient Education and Counseling, 86, 9-18. https:// doi.org/10.1016/j.pec.2011.02.004

Coran, J. J., Koropeckyj-Cox, T., \& Arnold, C. L. (2013). Are physicians and patients in agreement? Exploring dyadic concordance. Health Education \& Behavior, 40, 603-611. https://doi.org/ 10.1177/1090198112473102

Cousin, G., Schmid Mast, M., Roter, D. L., \& Hall, J. A. (2012). Concordance between physician communication style and patient attitudes predicts patient satisfaction. Patient Education and Counseling, 87, 193-197. https://doi.org/10.1016/j.pec.2011.08.004

Cousin, G., Schmid Mast, M., \& Jaunin-Stalder, N. (2013). Finding the right interactional temperature: Do colder patients need more warmth in physician communication style. Social Science \& Medicine, 98, 18-23. https://doi.org/10.1016/j. socscimed.2013.08.034

de Haes, H., \& Bensing, J. (2009). Endpoints in medical communication research, proposing a framework of functions and outcomes. Patient Education and Counseling, 74, 287-294. https://doi. org/10.1016/j.pec.2008.12.006 
Dréno, B., Thiboutot, D., Gollnick, H., Finlay, A. Y., Layton, A., Leyden, J. J., Leutenegger, E., Perez, M., \& Global Alliance to Improve Outcomes in Acne (2010). Large-scale worldwide observational study of adherence with acne therapy. International Journal of Dermatology, 49, 448-456. https://doi. org/10.1111/j.1365-4632.2010.04416.x

Fagerberg, C. R., Kragstrup, J., Støvring, H., \& Rasmussen, N. K. (1999). How well do patient and general practitioner agree about the content of consultations? Scandinavian Journal of Primary Health Care, 17, 149-152. https://doi.org/ 10.1080/028134399750002557

Gafni, A., Charles, C., \& Whelan, T. (1998). The physician-patient encounter: The physician as a perfect agent for the patient versus the informed treatment decision-making model. Social Science \& Medicine, 47, 347-354. https://doi.org/10.1016/ s0277-9536(98)00091-4

Gosling, S. D., John, O. P., Craik, K. H., \& Robins, R. W. (1998). Do people know how they behave? Selfreported act frequencies compared with on-line codings by observers. Journal of Personality and Social Psychology, 74, 1337-1349. https://doi.org/ 10.1037//0022-3514.74.5.1337

Griffin, S. J., Kinmonth, A. L., Veltman, M. W., Gillard, S., Grant, J., \& Stewart, M. (2004). Effect on health-related outcomes of interventions to alter the interaction between patients and practitioners: a systematic review of trials. Annals of Family Medicine, 2, 595-608. https://doi.org/10.1370/afm.142

Ha, J. F., \& Longnecker, N. (2010). Doctor-patient communication: a review. The Ochsner Journal, 10, 38-43.

Hall, W., Violato, C., Lewkonia, R., Lockyer, J., Fidler, H., Toews, J., Jennett, P., Donoff, M., \& Moores, D. (1999). Assessment of physician performance in Alberta: The physician achievement review. CMAJ: Canadian Medical Association Journal, 161, 52-57.

Hoyt, W. T., \& Kerns, M.-D. (1999). Magnitude and moderators of bias in observer ratings: a metaanalysis. Psychological Methods, 4, 403-424. https:// doi.org/10.1037/1082-989X.4.4.403

Janssen, S. M., \& Lagro-Janssen, A. L. (2012). Physician's gender, communication style, patient preferences and patient satisfaction in gynecology and obstetrics: a systematic review. Patient Education and Counseling, 89, 221-226. https://doi. org/10.1016/j.pec.2012.06.034

Jenkins, V., Fallowfield, L., \& Saul, J. (2001). Information needs of patients with cancer: Results from a large study in UK cancer centres. British Journal of Cancer, 84, 48-51. https://doi.org/10.1054/ bjoc. 2000.1573

Kardas, P., Lewek, P., \& Matyjaszczyk, M. (2013). Determinants of patient adherence: a review of systematic reviews. Frontiers in Pharmacology, 4, 91. https://doi.org/10.3389/fphar.2013.00091
Kenny, D. A., Veldhuijzen, W., van der Weijden, T., Leblanc, A., Lockyer, J., Légaré, F., \& Campbell, C. (2010). Interpersonal perception in the context of doctor-patient relationships: a dyadic analysis of doctor-patient communication. Social Science \& Medicine, 70, 763-768. https://doi.org/10.1016/j. socscimed.2009.10.065

Kim, S. S., Kaplowitz, S., \& Johnston, M. V. (2004). The effects of physician empathy on patient satisfaction and compliance. Evaluation \& the Health Professions, 27, 237-251. https://doi.org/10.1177/ 0163278704267037

Kowalewska, B., Jankowiak, B., Niedźwiecka, B., Krajewska-Kułak, E., Niczyporuk, W., \& Khvorik, D. (2020). Relationships between the acceptance of illness, quality of life and satisfaction with life in psoriasis. Advances in Dermatology and Allergology, 37, 948-955. https://doi.org/10.5114/ada.2020.92906

Krupat, E., Yeager, C. M., \& Putnam, S. (2000). Patient role orientations, doctor-patient fit, and visit satisfaction. Psychology \& Health, 15, 707-719. https://doi.org/10.1080/08870440008405481

Kurtz, S., Silverman, J., Benson, J., \& Draper, J. (2003). Marrying content and process in clinical method teaching: Enhancing the Calgary-Cambridge guides. Academic Medicine, 78, 802-809. https:// doi.org/10.1097/00001888-200308000-00011

Linder, D., \& Forchetti, G. (2009). Psoriasis and psyche - what's new? What is clinically relevant? Acta Dermatovenerologica Croatica, 17, 198-203.

Linder, D., Dall'Olio, E., Gisondi, P., Berardesca, E., Gennaro, E. D., Pennella, A. R., Giannetti, A., Peserico, A., \& Girolomoni, G. (2009). Perception of disease and doctor-patient relationship experienced by patients with psoriasis: a questionnaire-based study. American Journal of Clinical Dermatology, 10, 325-330. https://doi.org/10.2165/11311190-000000000-00000

Little, P., Everitt, H., Williamson, I., Warner, G., Moore, M., Gould, C., Ferrier, K., \& Payne, S. (2001). Observational study of effect of patient centredness and positive approach on outcomes of general practice consultations. BMJ, 323, 908-911. https:// doi.org/10.1136/bmj.323.7318.908

Magin, P., Adams, J., Heading, G., Pond, D., \& Smith, W. (2009). The psychological sequelae of psoriasis: Results of a qualitative study. Psychology, Health \& Medicine, 14, 150-161. https://doi. org/10.1080/13548500802512294

McCambridge, J., Witton, J., \& Elbourne, D. R. (2014). Systematic review of the Hawthorne effect: New concepts are needed to study research participation effects. Journal of Clinical Epidemiology, 67, 267-277. https://doi.org/10.1016/j.jclinepi.2013.08.015

Miniszewska, J., Chodkiewicz, J., Ograczyk-Piotrowska, A., \& Zalewska-Janowska, A. (2020). Life satisfaction and health related quality of life - the same or a different construct? A survey in psoria-
Patient-physician agreement on physicians' communication skills 
sis patients. Health Psychology Report, 8, 219-227. https://doi.org/10.5114/hpr.2020.95909

OECD/EU (2016). Health at a glance: Europe 2016. State of health in the EU cycle. OECD Publishing. https://doi.org/10.1787/9789264265592-en

Olson, D. P., \& Windish, D. M. (2010). Communication discrepancies between physicians and hospitalized patients. Archives of Internal Medicine, 170, 1302-1307. https://doi.org/10.1001/archinternmed.2010.239

Zuzanna

Kwissa-Gajewska, Aleksandra Kroemeke

Ong, L. M., de Haes, J. C., Hoos, A. M., \& Lammes, F. B. (1995). Doctor-patient communication: a review of the literature. Social Science \& Medicine, 40, 903918. https://doi.org/10.1016/0277-9536(94)00155-m

Overeem, K., Wollersheim, H. C., Arah, O. A., Cruijsberg, J. K., Grol, R. P., \& Lombarts, K. M. (2012). Evaluation of physicians' professional performance: an iterative development and validation study of multisource feedback instruments. $B M C$ Health Services Research, 12, 80. https://doi.org/ 10.1186/1472-6963-12-80

Poot, F. (2009). Doctor-patient relations in dermatology: Obligations and rights for a mutual satisfaction. Journal of the European Academy of Dermatology and Venereology, 23, 1233-1239. https://doi. org/10.1111/j.1468-3083.2009.03297.x

Probst, J. C., Greenhouse, D. L., \& Selassie, A. W. (1997). Patient and physician satisfaction with an outpatient care visit. The Journal of Family Practice, 45, 418-425.

Richards, H. L., Fortune, D. G., Weidmann, A., Sweeney, S. K. T., \& Griffiths, C. E. M. (2004). Detection of psychological distress in patients with psoriasis: Low consensus between dermatologist and patient. British Journal of Dermatology, 151, 1227-1233. https://doi.org/10.1111/j.1365-2133.2004.06221.x

Röttele, N., Schöpf-Lazzarino, A. C., Becker, S., Körner, M., Boeker, M., \& Wirtz, M. A. (2020). Agreement of physician and patient ratings of communication in medical encounters: a systematic review and meta-analysis of interrater agreement. Patient Education and Counseling, 103, 1873-1882. https://doi.org/10.1016/j.pec.2020.04.002

Röttele, N., Schlett, C., Körner, M., Farin-Glattacker, E., Schöpf-Lazzarino, A. C., Voigt-Radloff, S., \& Wirtz, M. A. (2021). Variance components of ratings of physician-patient communication: a generalizability theory analysis. PLoS One, 16, e0252968. https://doi.org/10.1371/journal.pone.0252968

Saba, G. W., Wong, S. T., Schillinger, D., Fernandez, A., Somkin, C. P., Wilson, C. C., \& Grumbach, K. (2006). Shared decision making and the experience of partnership in primary care. Annals of Family Medicine, 4, 54-62. https://doi.org/10.1370/afm.393

Sewitch, M. J., Abrahamowicz, M., Barkun, A., Bitton, A., Wild, G. E., Cohen, A., \& Dobkin, P. L. (2003). Patient nonadherence to medication in inflammatory bowel disease. The American Jour- nal of Gastroenterology, 98, 1535-1544. https://doi. org/10.1111/j.1572-0241.2003.07522.x

Shepherd, D. A. (2004). Educating entrepreneurship students about emotion and learning from failure. Academy of Management Learning \& Education, 3, 274-287. https://doi.org/10.5465/AMLE. 2004.14242217

Silverman, J., Kurtz, S., \& Draper, J. (2013). Skills for communicating with patients (3rd ed.). Radcliffe Publishing.

Smith, S., Adam, D., Kirkpatrick, P., \& McRobie, G. (2011). Using solution-focused communication to support patients. Nursing Standard, 25, 42-47. https://doi.org/10.7748/ns2011.08.25.52.42.c8675

Staiger, T. O., Jarvik, J. G., Deyo, R. A., Martin, B., \& Braddock, C. H. (2005). Brief report: Patientphysician agreement as a predictor of outcomes in patients with back pain. Journal of General Internal Medicine, 20, 935-937. https://doi.org/10.1111/ j.1525-1497.2005.0175.x

Stewart, M., Brown, J. B., Boon, H., Galajda, J., Meredith, L., \& Sangster, M. (1999). Evidence on patient-doctor communication. Cancer Prevention \& Control, 3, 25-30.

Stewart, M., Brown, J. B., Weston, W. W., McWhinney, I. R., McWilliam, C. L., \& Freeman, T. R. (1995). Patient-centered medicine: Transforming the clinical method. Sage Publications.

Stewart, M., Ryan, B. L., \& Bodea, C. (2011). Is patient-centred care associated with lower diagnostic costs? Healthcare Policy, 6, 27-31.

Street, R. L., \& Wiemann, J. M. (1987). Patients' satisfaction with physicians' interpersonal involvement, expressiveness, and dominance. Annals of the International Communication Association, 10, 591-612. https://doi.org/10.1080/23808985.1987.11 678664

Taube, K. M. (2016). Patient-doctor relationship in dermatology: From compliance to concordance. Acta Dermato-Venereologica, 96, 25-29.

Taylor, S. E. (2012). Health psychology (8th ed.). McGraw-Hill.

Uhlenhake, E. E., Kurkowski, D., \& Feldman, S. R. (2010). Conversations on psoriasis - what patients want and what physicians can provide: a qualitative look at patient and physician expectations. The Journal of Dermatological Treatment, 21, 6-12. https://doi.org/10.3109/09546630903085328

van den Brink-Muinen, A., Verhaak, P. F., Bensing, J. M., Bahrs, O., Deveugele, M., Gask, L., Leiva, F., Mead, N., Messerli, V., Oppizzi, L., Peltenburg, M., \& Perez, A. (2000). Doctor-patient communication in different European health care systems: Relevance and performance from the patients' perspective. Patient Education and Counseling, 39, 115-127. https://doi.org/10.1016/s0738-3991(99)00098-1

van Osch, M., van Dulmen, S., van Vliet, L., \& Bensing, J. (2017). Specifying the effects of physi- 
cian's communication on patients' outcomes: a randomised controlled trial. Patient Education and Counseling, 100, 1482-1489. https://doi.org/ 10.1016/j.pec.2017.03.009

Violato, C., \& Lockyer, J. (2006). Self and peer assessment of pediatricians, psychiatrists and medicine specialists: Implications for self-directed learning. Advances in Health Sciences Education: Theory and Practice, 11, 235-244. https://doi.org/10.1007/ s10459-005-5639-0

Williams, S., Weinman, J., \& Dale, J. (1998). Doctorpatient communication and patient satisfaction: a review. Family Practice, 15, 480-492. https://doi. org/10.1093/fampra/15.5.480

Wlodarczyk, D., Chylińska, J., Lazarewicz, M., Rzadkiewicz, M., Jaworski, M., Adamus, M., Haugan, G., Lillefjell, M., \& Espnes, G. A. (2017). Enhancing doctors' competencies in communication with and activation of older patients: The Promoting Active Aging (PRACTA) computer-based intervention study. Journal of Medical Internet Research, 19, e45. https://doi.org/10.2196/jmir.6948

World Health Organization (2016). Global report on psoriasis. Retrieved from http://www.who.int/iris/ handle/10665/204417

Worthington, R. L., Mobley, M., Franks, R. P., \& Tan, J. A. (2000). Multicultural counseling competencies: Verbal content, counselor attributions, and social desirability. Journal of Counseling Psychology, 47, 460-468. https://doi.org/10.1037/0022-0167.47.4.460

Zandbelt, L. C., Smets, E. M., Oort, F. J., Godfried, M. H., \& de Haes, H. C. (2004). Satisfaction with the outpatient encounter: a comparison of patients' and physicians' views. Journal of General Internal Medicine, 19, 1088-1095. https://doi. org/10.1111/j.1525-1497.2004.30420.x 